\title{
Early-Age Shrinkage of High-Performance Concrete Beam in Laboratory and Full-Scale
}

\author{
Chatarina Niken \\ University of Lampung, Jl. Sumatri Brojonegoro No 1 Bandar Lampung, Indonesia
}

\begin{abstract}
The beam is a significant element structure in bridge and high - rise building. The aim of this study is to obtain the difference of early age shrinkage between beam with laboratory scale and full scale. High-performance concrete with compressive strength of $60 \mathrm{MPa}$ was used. This research was done experimentally in Indonesia for 24 hours. Three pieces of specimens measuring laboratory size of $150 \mathrm{~mm} \times 150 \mathrm{~mm} \times 600 \mathrm{~mm}$, and one specimen measuring $200 \mathrm{~mm} \times 600 \mathrm{~mm} \times 3000 \mathrm{~mm}$ as full - scale specimen were used. All specimens were covered with styrofoam to eliminate transfer humidity. Early age shrinkage was obtained by using an embedded vibrating wire strain gauge for each laboratory size specimen and four embedded vibrating wire strain gauge for the full-scale specimen. As a result, the shrinkage type of full- scale specimen is a similar type to laboratory size. Shrinkage in laboratory size specimen is $31.5 \%$ larger than in full-scale specimen. Maximum shrinkage in a fullscale specimen is about $0.8 \mathrm{E}-04$ occurs at the concrete age of 15.8 hours, while in laboratory size specimen is about 1.255E-04 occur at the age of 22.2 hours. Fluctuation expansion and shrinkage are smoother in full-scale than in laboratory size specimen. This is because in full-scale ettringite can expand more optimally so that it can come with stand shrinkage losses due to the growth of hydration products. High rate deformation of both specimens scale is occurring in the age range of 5-9 hours. Therefore, it is safe to assume the behavior of a real beam of high-performance concrete similar to laboratory size beam.
\end{abstract}

Keywords: Beam, Concrete, Early, Shrinkage, Size

DOI: $10.7176 / \mathrm{CER} / 11-4-05$

Publication date:May $31^{\text {st }} 2019$

\section{Introduction}

Understanding of early ages behavior is very important and useful for the design of durable and sustainable structures (Klemczak and Wroble, 2011). Volume change of concrete resulting from structural and environmental factors are the acceptable phenomenon. In reality, a volume change commences immediately after the cement and water come in contact during concrete mixing. Shrinkage of the concrete takes place in two distinct stages: early and later ages. The early stage is commonly defined as the first day, while the concrete is setting and starting to harden. Later ages, or long term, refers to the concrete at the age of 24 hours and beyond (Bažant, 2012).

These early age volume changes are typically ignored in the design of concrete structures since their magnitude can be much less than shrinkage resulting from drying. But even when the concrete curing condition is ideal, the first-day shrinkage can significantly contribute to the ultimate shrinkage and thus the cracking risk (Bažant, 2012). The difference of long-term deformation in column sand beams is in their early-age deformation behavior (Niken et al., 2017). Cutting at rigid pavement should be done at the age of 5-8 hour to prevent early or microcracking. Early cracking can growth to macro-crack. Nonuniform residual stresses are relaxing due to creep, and microcracking affects the average shrinkage of a cross-section of long members (Hubler et al., 2015).

The major incident at an early age is hydration. Hydration is a chemical process. The chemical process always correlated to volume change. It is merely a result of the internal chemical and structural reactions of the concrete components. Enough water for this process is really important; thus, no moisture transfer should be avoided. Autogenous shrinkage is a volume change resulting when there is no moisture transfer to the surrounding environment. Moisture movement caused by capillary condensation was thought to be the cause of flexural strength reduction for sealed specimens (Tazawa and Mujazawa, 1995). Effects of water-binder ratio on autogenous shrinkage were studied ( Zhang et al., 2015). Autogenous shrinkage is usually a concern in high strength or high-performance concrete $(>40 \mathrm{MPa}$ or $6000 \mathrm{psi}$ ) where there is a low water-to-cement (w/c) ratio. The shrinkage was well correlated to the cement' chemistry and the development of internal capillary pressure within the cement paste (Holt, 2001).

Autogenous shrinkage has a different physical mechanism and is important for modern high-performance concrete (HPC), very and ultra-high-performance concrete with admixtures, additive and low water-cement ratio. Some admixtures which were able to reduce autogenous were found (Tazawa \& Miyazawa 1, 1995). Paillere et al., 1989 was found that in very high-strength silica fume, concrete undergoes early cracking when deformation is restrained. This phenomenon attributed to an intense autogenous shrinkage of the concrete exceptionally low $\mathrm{w} / \mathrm{c}(0.26)$.

Admixture and additive generally used in making self-consolidating concrete (SCC). Early autogenous 
shrinkage of self-consolidating concrete was also published (Li and Li, 2014). Long et al., 2011 was studied autogenous shrinkage of prestressed SCC. Soliman, 2011, have studied early-age shrinkage of ultra-highperformance concrete. Jun et al., 2011 was developed an autogenous shrinkage model base on chemical shrinkage and interior humidity reduction. The model agrees well with experimental measurement of autogenous shrinkage in early age normal and high strength concrete.

Concrete as quasi-brittle structures fail at the macro-crack initiation which can appear from the microcrack growth. The characteristic is a strong non-statistical size effect on both the structural strength and on the rate of creep and shrinkage (caused by size dependence of the drying rate). This kind of size effect is by now universally accepted by the IA-FRAMCOS and by the Engineering Mechanics Institute of ASCE, and also by the ACI Committees 446 (Fracture Mechanics) and 447 (Finite Element Analysis) which, unfortunately, have almost no say on the ACI design code formulation. The size effect is now widely acknowledged to be a serious issue even in the ACI code-making committees, ACI 318 and 445 (Hubler et al., 2015). The size dependency of the fracture energy and the effective length of the fracture process zone of concrete determine as per the Bažant size effect method and RILEM work-of fracture methods (Rao, 2013). Safety factors for quasi-brittle structures should significantly increase with structure size (Bažant, 2012).

The beam is the primary element structure in frames and bridges. Beam failure causes the fail of bridges. Base on the mention above, the research of difference early age behavior between laboratory size specimen and full-scale is needed especially for high-performance concrete.

\section{Experimental Programme}

The research was conducted in Jakarta, Indonesia, with humid tropical weather. This research was performed experimentally using three specimens of $150 \mathrm{~mm} \times 150 \mathrm{~mm} \times 600 \mathrm{~mm}$ for the flexural test according to ASTM C78-08, with one embedded vibrating wire strain gauge (EVWSG) per specimen and one full-scale specimen of $200 \mathrm{~mm} \times 600 \mathrm{~mm} \times 3000 \mathrm{~mm}$. The shrinkage in the beam center was affected by the maximum deflection. Based on this study, the position of the EVWSG was at the end of the beam, $5 \mathrm{~cm}$ for laboratory size (Figure 1a) and $70 \mathrm{~cm}$ for the full-scale specimen (Figure 1b). HPC with a target compressive strength of $60 \mathrm{MPa}$ and slump flow diameter of $35 \pm 2 \mathrm{~cm}$ were used.

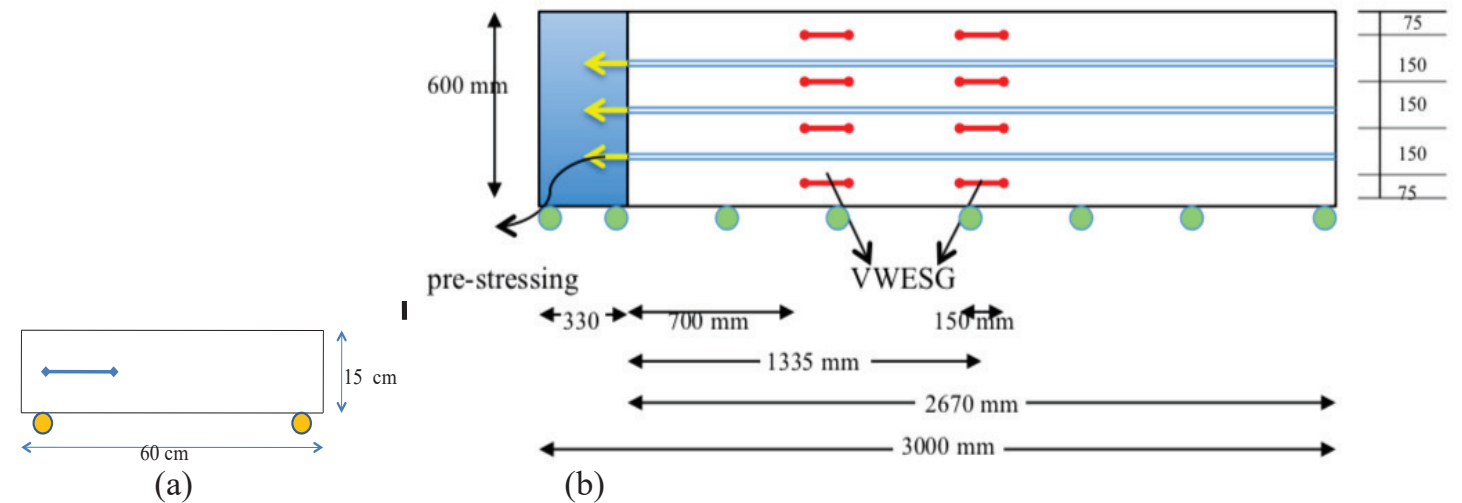

(a)

Figure 1: (a) Laboratory size specimen; (b) Full-scale specimen

\subsection{Materials}

The mix design was conducted in compliance with ACI $211.4 \mathrm{R}$ (1993) with a limit of $500 \mathrm{~kg} / \mathrm{m} 3 \mathrm{cement}$ content to meet the shrinkage factor closest to 1 (ACI 209R, 1992). Ordinary Portland Cement (OPC) produced by Indocement Ltd was used. The condition of the aggregate was saturated surface dry (SSD). Fine aggregate in the form of river sand was brought from Sungai Liat (Bangka, Sumatra, Indonesia), specific gravity (SSD) was 2.605, and absorption was $0.4 \%$. The sand had been filtered and cleaned using a mixture of standard graphs obtained from the mid-gradation. Fine aggregate shall be free of the injurious amount of organic impurities (American Society for Testing and Materials International, 2002). Coarse aggregate in the form of volcanic rock fragments was obtained from Banten, West Java, Indonesia. The composition of the coarse aggregate used was $70 \%$ sized 13 - 19mm, specific gravity (SSD) of 2.563, absorption of $1.543 \%$, and $30 \%$ sized $6-12 \mathrm{~mm}$, a specific gravity of 2.636, and absorption of $2.26 \%$.

The added material used was silica fume of $8 \%$ cement weight, produced by Sika Indonesia Ltd. To achieve the desired high strength with a low ratio of water to cementitious material and excellent workability, polycarboxylic super plasticizer under the commercial name Visco Crete 10 from Sika Indonesia Ltd was added to the concrete mix at the high range water reducer (HRWR). A dose of HRWR of $1.4 \%$ cement weight was added according to that generally used in Indonesia. The local water was supplied by the Structure and Material Laboratory of Universitas Indonesia. An electrical scale was used for cementitious material sand water to obtain 
the accurate ratio of water to cementitious material.

The mix composition was $500 \mathrm{~kg} / \mathrm{m} 3$ of OPC, $40 \mathrm{~kg} / \mathrm{m} 3$ of silica fume, $142.6 \mathrm{~kg} / \mathrm{m} 3$ of water, $800 \mathrm{~kg} / \mathrm{m} 3 \mathrm{of}$ sand, $935 \mathrm{~kg} / \mathrm{m} 3$ of coarse aggregate, and $7.6 \mathrm{~kg} / \mathrm{m} 3$ of HRWR. During the concrete mix design stage, all of the aggregates was assumed to be an undersaturated surface-dry condition. A tilting drum mixture with a $0.3 \mathrm{~m} 3$ capacity was used. The mixing started with all cementitious material in a dry condition, followed with $50 \%$ fine aggregate. Subsequently, $50 \%$ of water was added to the revolving mixture. Then, these materials were mixed for approximately $1 \frac{1}{2}$ minutes. Next, $50 \%$ of water was slowly poured in, which was homogenously mixed with HRWR. After that, 100\% coarse and 50\% fine aggregate was added. With all the materials placed according to their order into the mixer, the concrete was mixed for approximately 3 minutes. The slump flow of the mixture was measured before pouring by using an Abrams cone upside down.

\subsection{Methods}

In this research, shrinkage was measured as strain change against time by installing one EVWSG in each specimen, and four EVWSGs in a full-scale specimen (Figures 1a and 1b). The EVWSG was able to detect the strain up to $3000 \mu \varepsilon$ with an accuracy of about $.025 \%$ and concrete temperature between $-80 \mathrm{oC}$ and $60 \mathrm{oC}$ with about .5\% accuracy. Right after casting, specimens were covered with styrofoam to eliminate water evaporation (Figure 2).

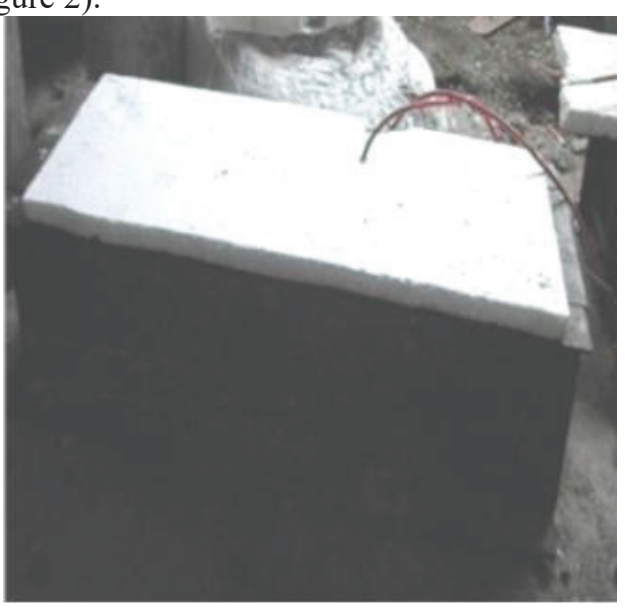

(a)

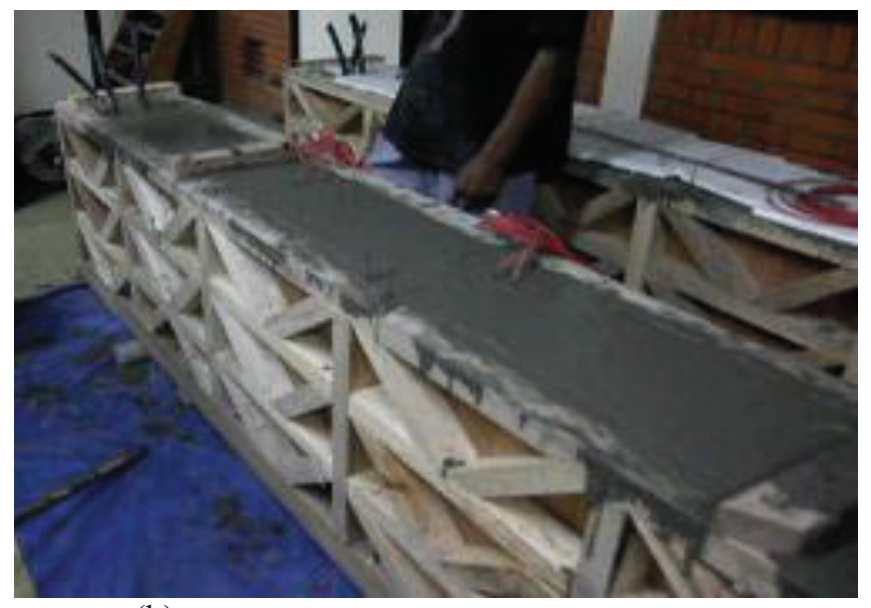

(b)

Figure 2. Styrofoam were covered specimen: (a) Laboratory size specimen, (b) Full-scale specimen

The observation was performed right after pouring every 15 minutes until 24 hours using a readout. Data of the three beam laboratory size specimens were analyzed using Dixon's criteria as the standard practice for dealing with outlying observation. ASTM E 178-02 has mentioned that Dixon criteria, based entirely on ratios of differences between the observations may be used in cases where it is desirable to avoid calculation of standard deviation or where quick judgment is called for. For a Dixon test, the sample criterion or statistic changes with sample size. The equations of the Dixon criteria for 3 to 7 samples with $\mathrm{x}_{1} \leq \mathrm{x}_{2} \leq \ldots \leq \mathrm{x}_{\mathrm{n}}$ are as follows.

If smallest value is suspected: $\quad$ r10 $\quad=\left(\mathrm{x}_{2}-\mathrm{x}_{1}\right) /\left(\mathrm{x}_{\mathrm{n}}-\mathrm{x}_{1}\right)$

If largest value is suspected: $\quad \mathrm{r} 10 \quad=\left(\mathrm{x}_{\mathrm{n}}-\mathrm{x}_{\mathrm{n}-1}\right) /\left(\mathrm{x}_{\mathrm{n}}-\mathrm{x}_{1}\right)$

Using Equations 1 and 2 for data at ages with large difference of shrinkage from the 3 specimens were computed. Shrinkage of laboratory size specimens was found by using average of accepted data. Shrinkage of the full-scale specimen was found by using the average value of all VWESG. Both shrinkages were compared and by using literature study the conclusion can be obtained.

\section{Result}

The results of research from laboratory size specimens are presented separately, and then the mean results are presented together with the results of full-scale processing.

\subsection{Shrinkage of Laboratory Size Specimens}

From the third specimen, considerable different shrinkage value occurs at the age of 7-17 hour (Figure 3a). By using a 5\% significance level, we anticipated both suspects: largest and smallest. The age range of 7-17 hour was selected because at this age the shrinkage difference is significant (Figure 3a). By anticipating both suspects, the r10 graph may appear fluctuating and oppositional (Figure 3b). 


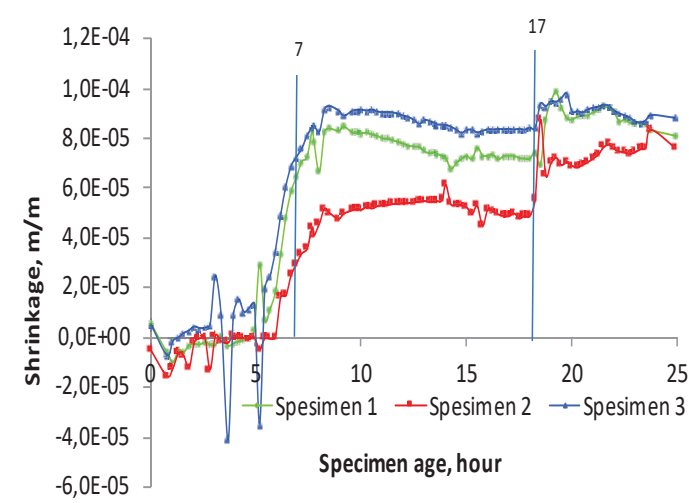

(a)

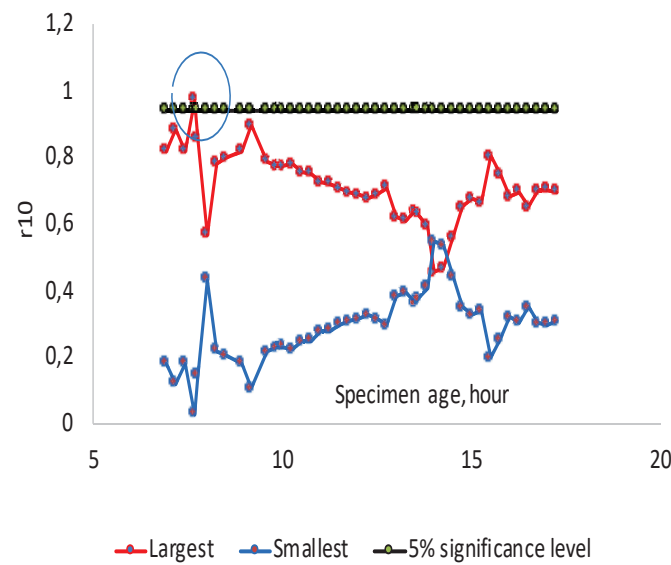

(b)

Figure 3. (a) shrinkage of three laboratory specimens, (b) Outlying graph

There is one data from 94 data, or one percent is over the 5\% significance level (Figure $3 \mathrm{~b}$ ); therefore, all of the data were used to define the shrinkage of laboratory size specimen by using an average value.

\subsection{Shrinkage of Laboratory Size and Full - Scale Specimens}

Comparison of early age behavior which is happening in laboratory size and full - scale specimen can be seen in Fig. 4.

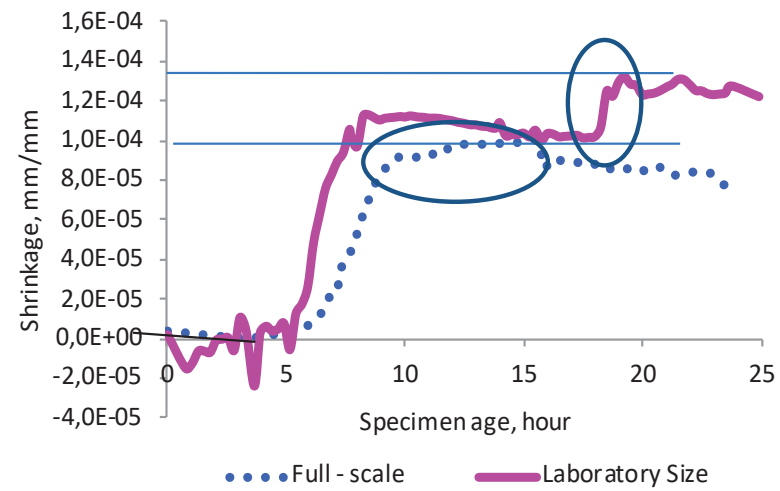

Figure 4. Early age behaviour in laboratory size and full-scale specimens

\section{Discussion}

Early-age shrinkage in full - scale specimen is smaller than in laboratory size specimen, but with a smooth curve. The fluctuation between expansion and shrinkage in laboratory specimens is more than in full-scale specimen (Fig. 4). The phenomenon represents the change of the macroscopic behavior of concrete directly related to the modification of the internal material structure, which, in turn, is due to the evolution of nano- and micro-scale physical mechanisms and chemical reactions.

Right after cement, silica fume converges with water, dissolution and diffusion occur. Particles scattered and expansion volume occur. It leads to the chemical reaction process. The chemical reaction rate depends on the concrete age. Two main early- age reactions can be identified: cement hydration-the reaction of free-water with un-hydrated cement particles, and silica-fume reaction; the reaction of silica particles with portlandite or $\mathrm{CaOH} 2$ (Di Luzio and Cusatis, 2009a). CH and ettringite were formed right after mixing (Fig. 5). The reaction makes concrete become porous media. Distribution of pores dimension is including extensive range. Pores with a minimum diameter of $0.5 \mathrm{~nm}$, were formed between C-S-H gel. Morin et al., 2002 was mentioned there are two pores class. Pores with a dimension of 10-20 nm start when concrete reach solid hyperstatic state and about 1-2 $\mathrm{nm}$. The first was correlated to pores space of cluster hydrate C-S-H, and the second is related to the porosity of internal hydrate.

A porous media consists of a solid porous matrix saturated by one or more liquid phases. There are interactions and momentum exchanges between the fluid phases and between these and the solid skeleton (Klemczak and Wroble, 2011). Hence, part of the strains is associated with fluids-solid mechanical interactions (Klemczak and Wroble, 2011). Inter-connectivity of pores was affected by age, size, and shape. Environment affects the interactions and momentum exchange. All of the specimens in this research are covered by styrofoam; therefore, the porous medium is not in hygral equilibrium between the internal and external environment, 
particles interaction and momentum exchanges occur without environmental influences. The consequence of its mass transport of the different fluid phases and species occurs. Mass exchanges between the different phases of the system may arise (Klemczak and Wroble, 2011). Mass exchange and hydration caused by micro-prestress and it leads to strain in concrete. The concrete strain appears as shrinkage and expansions as a behavior of concrete (Fig.4). The macroscopic behavior of a porous medium is significantly connected with the microstructure of the solid matrix and with the micro-scale physics. Sometimes the macroscopic behavior cannot be explained exhaustively at the macroscale but depends on well-known microscopic phenomena; in that case, the introduction of closure relationships at the microscale can be helpful (Klemczak and Wroble, 2011).

Hydration gives a significant contribution to concrete behavior at an early age. Hydration product growth can be shown in Fig. 5.

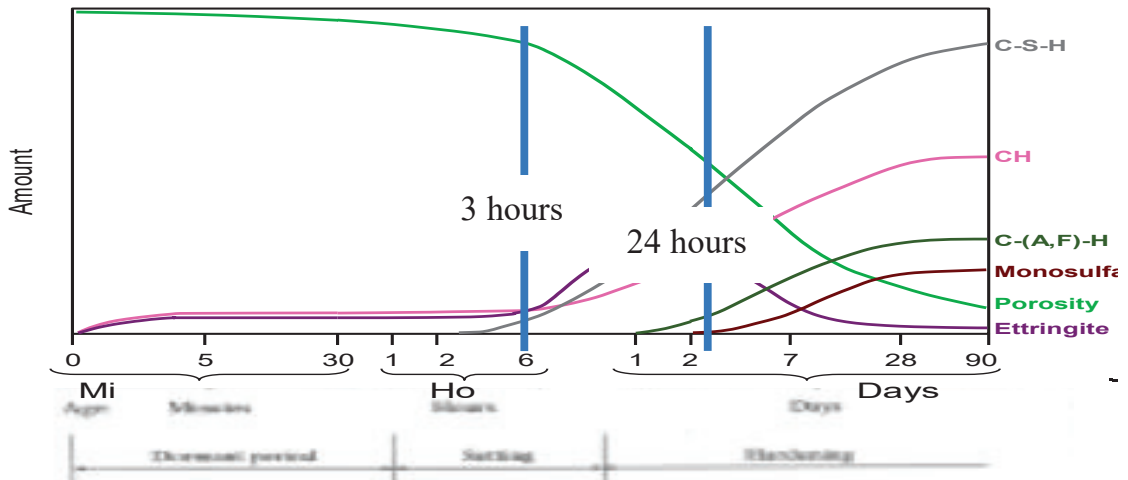

(a)

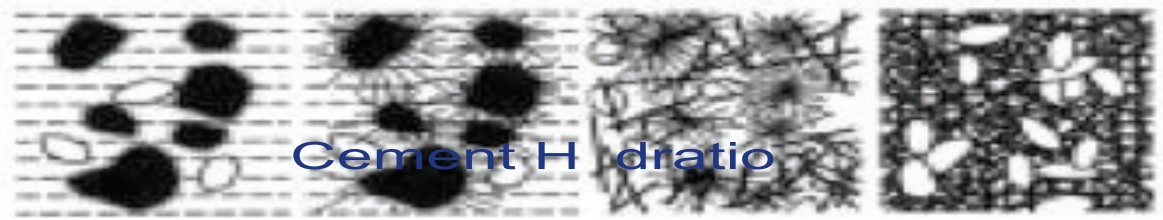

(b)

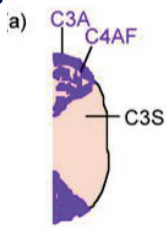

(b)

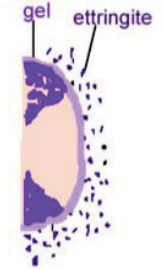

Un-hydrated cement 10 minute

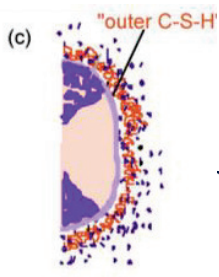

10 hour

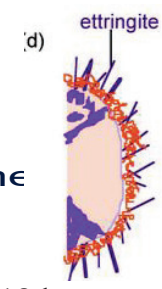

18 hour

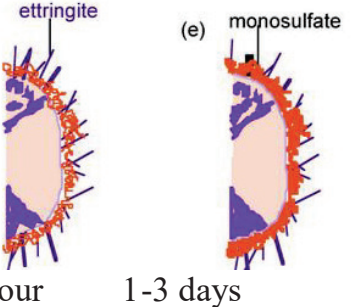

1-3 days

(c)

Fig. 5. Product hydration growth and cement hydration scheme: $(\mathrm{a}, \mathrm{b})$ Product hydration growth and concrete growth period (Kurtis, 2015), (c ) Cement hydration scheme (Taylor, 1997)

The reactions cause evolution shape and properties of the material. Evolution of material properties depends on hydration degree. The early-age development of material properties requires the preliminary calculation of hydration degree, humidity, and temperature (Di Luzio and Cusatis, 2009a,b). The change of temperature and inner humidity occurs only by chemical reaction of cement hydration, silica fume pozzolanic reaction and silicate polymerization because the specimens are protected against external influences. The coupled effect of the chemical reaction influences moisture transport and heat transfer in the specimens. The reactions make constituent to be solid and gradually becoming hardener according to hydration degree (Fig. 5b). The hydration degree affects the volume growth of the solidifying constituent. The solidifying constituent is assumed to be ageindependent and the chemical aging (Di Luzio and Cusatis, 2013). Chemical reaction and behavior of alite should be the concern because of approximately alite typically about $50-80 \%$ of the total cement (Kumar et al., 2012). Because of that, concrete behavior was affected by alite hydration which was $\mathrm{Ca}^{2+}$ as shown in Fig. 6 ., and $\mathrm{Ca} 2+$ caused the expansion to occur in the concrete. 


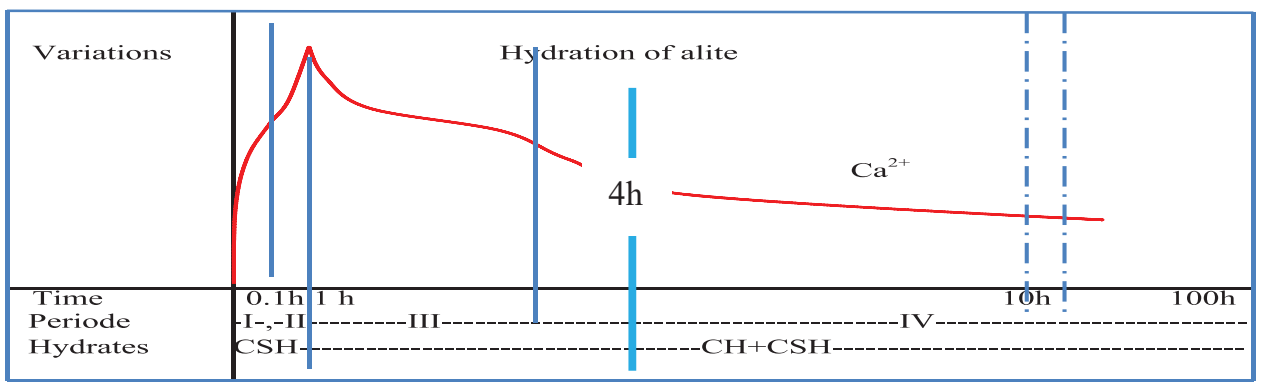

Fig. 6. Alite hydration (Paulini, 1990)

The ability of ettringite, $\mathrm{Ca}^{2+}$, and pressure lead to concrete expansion, while product hydration growth makes shrinkage because product hydration volume is less than its ingredients (Fig. 6).

Duration of expansion and shrinkage for full scale and laboratory specimens as described in Fig. 4 can be seen in Table 1.

Table 1. Full scale and laboratory scale specimens behavior

\begin{tabular}{|c|c|c|c|c|c|}
\hline \multirow[t]{2}{*}{ Behavior } & \multicolumn{2}{|c|}{ Duration (hour) } & \multirow[t]{2}{*}{ Behavior } & \multicolumn{2}{|c|}{ Duration (hour) } \\
\hline & $\begin{array}{c}\text { Laboratory } \\
\text { Scale }\end{array}$ & Full- Scale & & $\begin{array}{c}\text { Laboratory } \\
\text { Scale }\end{array}$ & Full-Scale \\
\hline Expansion & 0.75 & 4.3 & Expansion & 9.1 & \\
\hline Slow rate shrinkage & 4.65 & 2.3 & Shrinkage & 1.5 & 5.5 \\
\hline High rate shrinkage & 3.5 & 3.2 & Expansion & 4.5 & 8.7 \\
\hline
\end{tabular}

In the first hour, the highest expansion can be occurred because of highest $\mathrm{Ca}^{2+}$ (Fig. 6). This matter is fit with laboratory scale behavior (Fig. 4). In full scale, expansion appears with low slope but with a longer duration that is 4.3 hours or 5.7 than in laboratory specimens (Table 1, Fig.4). In full-scale specimen, $\mathrm{Ca}^{2+}$ and ettringite can expand more freely than in laboratory specimen cause expand of volume to be larger than shrinkage caused by $\mathrm{CH}$. The volume expansion occurs until $\mathrm{Ca}^{2+}$ almost constant (Fig. 4). In laboratory specimens, the expansion occurs only until the peak of $\mathrm{Ca}^{2+}$, furthermore, shrinkage by $\mathrm{CH}$ dominate. At the range time of $4.75-6.5$ hour, setting time also generally occur (Piyasena et al., 2013). At the age of 5 hours, both type specimens have similar value (Fig.4)

In the age range of 5-9 hour, high rate shrinkage occurs in both specimens with similar duration (Fig.4 and Table 1). Ettringite reaches a maximum value, $\mathrm{C}-\mathrm{S}-\mathrm{H}$ and $\mathrm{CH}$ rate showing a slight increase (Fig. 5) and $\mathrm{Ca}^{2+}$ reach constant value (Fig. 6). Rate and magnitude of shrinkage in laboratory specimen are more than in full scale. It can be cured because the chemical reaction in full scale occurs under pressure by specimen weight its self. This causes the volume to develop abnormally (Van Vlack, 1973).

In the age range of 9-18 hour, the full scale was shrunk with a low rate, and laboratory specimen was expanded with low rate until reach same value at the age of 15 (Fig. 4). It means, at the age of 9-15, the influence expansion by $\mathrm{Ca}^{2+}$ and increasing ettringite needles are smaller than shrinkage caused by the growth of outer $\mathrm{C}$ $\mathrm{S}-\mathrm{H}$ (Fig. 5b), by $\mathrm{CH}$, and by decreasing pores (Fig. 5a and Fig. 6). Decreasing pores number in full scale is more than in laboratory specimen because of weight its self, makes deformation rate to be slow.

In the age of 15-20 hour, there is only one shrinkage mechanism in full scale; while in laboratory specimen, there is two mechanism behavior: shrinkage with high rate during 1.5 hours and followed by expansion. At the age of 15 hours, the rate growth of ettringite is highest, and C-S-H start to increase. It makes the laboratory specimen show high rate shrinkage. Expansion in both specimens occurs because chemical reaction happens under product hydration growth stress and mass transport due to decreasing pores number.

At the age of 20-24 hours, both specimens have similar behavior that is an expansion (Fig. 4). At this time reaction of simple ions to form complex ions, or complex ions were absorbed in solid surface ettringite needles become longer and in maximum number condition. At the age, concrete starts to have its strength (Fig. 5a, 5b). Reactions of generating calcium-silicate-hydrates (C-S-H) which is the main constituent providing stiffness and strength. Similarly, the silica-fume response can be described through the ratio between the amount of reacted silica-fume and the total amount of silica-fume (Di Luzio and Cusatis, 2009a). There are more inner C-S-H and silica bridges, and they are stronger than before. All of the phenomena caused swelling more dominant than shrinkage.

\section{Conclusion}

Full-scale beam behavior is similar to a laboratory size specimen. Maximum shrinkage in full-scale specimen occurs at the age of 15.8 hours with shrinkage value of $0,86 \mathrm{E}-04$, while in laboratory size specimen occurs at the age of 22.2 hours with shrinkage value of $1.255 \mathrm{E}-04$; therefore, shrinkage in laboratory specimens $31.5 \%$ more than full-scale. The fluctuation between expansion and shrinkage are smoother in full-scale than in laboratory 
size specimen. This is because expansion volume caused by $\mathrm{Ca}^{2+}$, ettringite, and pressure by beam weight its self has more space so that can decrease shrinkage.

The expansion and solution are easier in full-scale specimen than in laboratory scale specimens. Expansion with a long duration can be obtained at the end of the first day. This condition correlated with the available maximum ettringite at the end of the first day with a long duration. Shrinkage caused by C-S-H growth is similar for both specimens, with more significant rate and number in laboratory specimen than in full-scale specimens. This condition caused by pressure from weight its self on particles which was in a chemical reaction, makes expansion volume reduce shrinkage number.

It is safe to real treatment beam by assuming similar behavior with laboratory scale specimen.

\section{Aknowledment}

We would like to thanks the University of Lampung for supporting our research, for the University of Indonesia (UI) for the funding provided to this research. Also, our thanks to Sika Indonesia Ltd and Indocement Ltd for their full support materials. Besides, thank you for the technical staff of Structures and Materials Laboratory, Faculty of Civil Engineering, the University of Indonesia for their technical support in conducting the experiments.

\section{References}

1. ACI 209R-92. (1992). Prediction of creep, shrinkage, and temperature effects in concrete structure. American Concrete Institute, pp. 1-47

2. ACI 211.4R. (1993). Guide for Selecting Proportion for High Strength Concrete with Portland Cement and Fly Ash. International Concrete Abstracts Portal, Volume 90, pp. 272-283

3. ASTM C78/C78M-18. (2002). Standard Test Method for Flexural Strength of Concrete. American Society for Testing and Materials,

4. ASTM E178-02, (2002). Standard practice for dealing with outlying observation. American Society for Testing and Materials, pp. 1-18.

5. Bažant Z.P., (2012). Rational and Safe Design of Concrete Transportation Structures for Size Effect and Multi Decade Sustainability. Technical Report. Safetea-LU Project, Infrastructure Technology Institute, Northwestern University, Illinois. 26 pages.

6. Di Luzio G., Cusatis G., (2013). Solidification-microprestress-microplane (SMM) Theory for Concrete at Early-age: Theory, Validation and Application. International Journal of Solids and Structures. Vol. 50, pp. 957-975.

7. Holt, E.E., (2001). Early Age Autogenous Shrinkage of Concrete. UTT Publication, Technical Research Centre of Finland. 184 pages

8. Hubler M.H., Wendner R.,Bažant Z.P., (2015). Statistical Justification of Model B4 for Drying and Autogenous Shrinkage of Concrete and Comparison to Other Models. Materials and Structures Journal. Vol. 48 (4), pp. 797-814.

9. Jun. Z., Dongwei. H., Haoyou. C., (2011). Experimental and Theoretical Studies on Autogenous Shrinkage at Early Ages. Journal of Materials in Civil Engineering, Vol. 23 (3), pp. 312-320.

10. Klemczak B., Knoppik-Wrobel A., (2011). Early-age Thermal and Shrinkage Cracks in Concrete Structures Description of the Problem. Architecture Civil Engineering Environment, pp. 35-47

11. Kumar, A., Bishnoi, S., Scrivener, K.L., (2012). Modelling Early-age Hydration Kinetics of Alite. Journal of Cement and Concrete Research, Vol. 42, pp. 903-918

12. Kurtis, K., (2015). Portland cement hydration. School of civil engineering, Georgia Institute of Technology, Atlanta, Georgia, 69 slides.

13. Li Y., and Li J., (2014). Capillary Tension Theory for Prediction of Early Autogenous Shrinkage of Self Consolidating Concrete. Construction and Building Materials Journal. Vol. 53, pp 511-516.

14. Long. W.J., Khayat. K.H., Xing. F., (2011). Autogenous Shrinkage of Prestressed Self-Consolidation Concrete. The Open Civil Engineering Journal. Vol. 5, pp. 116-123.

15. Morin, V., Cohen-Tenoudji, F., Feylessouti, A., 2002, Evolution of the Capillary Network in a Reactive Powder Concrete During Hydration Process. Journal of Cement and Concrete Research, Volume 32, pp. $1,907-1,914$.

16. Niken C., Elly, T., Supartono, F.X., (2017), Long-term Deformation of Beam and Column of High Performance Concrete. International Journal of Technology, Vol. 8(5)

17. Paillere A.M., Buil M., and Serrano J.J., (1989). Effect of Fibre Addition on the Autogenous Shrinkage of Silica fume. Material Journal. Vol. 86 (2), pp. 139-144.

18. Paulini, P. (1990). Reaction mechanisms of concrete admixture. Cement and concrete research. Vol. 20, pp. 910-918.

19. Piyasena, R.R.C., Premerathne, P.A.T.S., Perera, B.T.D., Nanayakkara, S.M.A., (2013). Evaluation of Initial 
Setting Time of Fresh Concrete. National Engineering Conference19th ERU Symposium, Faculty of Engineering, University of Moratuwa, Sri Lanka, pp. 47-52.

20. Rao T.M., and Rao T.D.G., (2013). Size Effect of Plane Concrete Beams- an Experimental Study. International Journal of Research in Engineering and Technology. Vol. 02 (06), pp. 1047-1051

21. Soliman, A.M., (2011). Early-age Shrinkage of Ultra High-Performance Concrete: Mitigation and Compensating Mechanism, Dessertation Repository, University of Western Ontario.

22. Tazawa E., and Mujazawa S., (1995). Influence of Cement and Admixture on Autogenous Shrinkage of Paste. Cement and Concrete Research Journal. Vol. 25 (2), pp. 281-287.

23. Tazawa E., and Mujazawa S., (1995). Experimental study on Mechanism of Autogenous Shrinkage of Concrete. Cement and Concrete Research Journal. Vol. 25 (8), pp. 1633-1638.

24. Van Vlack, L.H, 1973, Materials Science for Engineers, Addison Wesley, Canada, USA.

25. Zhang J., Han Y.D., Gao Y., (2014). Effect of Water-Binder Ratio and Coarse Aggregate Content on Interior Humidity, Autogenous Shrinkage and Drying Shrinkage of Concrete. Journal of Materials in Civil Engineering. Vol. 26 (1). 